\title{
Departmental Action Teams: Empowering faculty to make sustainable change
}

\author{
Joel C. Corbo, ${ }^{1}$ Daniel L. Reinholz, ${ }^{1}$ Melissa H. Dancy ${ }^{2}$ and Noah Finkelstein ${ }^{2}$ \\ ${ }^{1}$ Center for STEM Learning, University of Colorado, Boulder, CO 80309 \\ ${ }^{2}$ Department of Physics, University of Colorado, Boulder, CO 80309
}

\begin{abstract}
We describe a new type of faculty working group, a Departmental Action Team (DAT), that forms one component of a larger strategy towards enacting cultural change in higher education. DATs empower a team of faculty members within a single department to make focused, sustainable change in their department. DATs focus on departmental development, supporting faculty in designing and implementing structures to address an educational problem of mutual interest and broad-scale importance to their department (rather than trying to "solve" the problem themselves). This contrasts other faculty development efforts like Faculty Learning Communities (FLCs), which support the individual development of faculty from different departments through reflection on separate education projects. We contextualize the DAT model through a case study of a group that is focused on improving gender and racial equity among their undergraduate majors.
\end{abstract}

PACS numbers: 01.40.Fk,01.30.Cc

\section{INTRODUCTION}

Recent national calls stress the importance of reforming science, technology, engineering, and math (STEM) education to support more student-centered educational methods $[1,2]$. Most work along these lines has focused on individual courses, primarily through developing and disseminating new teaching methods or through developing reflective teachers. While physics education research (PER) has made great advances in developing course transformations and measures of student learning, recent work has brought attention to issues related to sustaining and scaling these innovations $[3,4]$. Pedagogy at the individual course level is important, but efforts that impact larger departmental structures are also required to support broad-scale and sustained educational change, rather than change that is localized and temporary. Ultimately, systemic factors determine the extent to which new innovations are adopted and sustained [5], so efforts that attend to a department holistically are much more likely to result in lasting improvements [6].

This paper provides a new model for supporting change in physics and other STEM disciplines through the formation of Departmental Action Teams (DATs). A DAT is a new type of faculty working group that we have been piloting for the last academic year. DATs aim to address educational issues of department-wide interest (e.g., coordination of courses across the curriculum or diversity of the student population). Because such issues are rarely "solved" through one-time events, DATs work to create new department structures for addressing the issue on an ongoing basis. Hence, DATs are designed to create sustainable departmental change by supporting their participants in learning about the change process, feeling empowered to make change, and creating mechanisms through which the department can continually learn and improve as it changes.

We briefly describe the structure and theoretical basis for DATs, and then we discuss one of them as an example. This work is part the STEM Institutional Transformation
Action Research (SITAR) Project, which is a multi-year project focused on institutional change.

\section{DEPARTMENTAL ACTION TEAMS}

DATs help their participants learn about change, feel able to make change, and work collectively to enact change, all with respect to an educational need they see in their department. These goals are supported by external facilitation, collaboration in a community, participant diversity, and flexibility and adaptability in the DAT's activities based on the participants' needs.

\section{A. Structure of a DAT}

DATs consist of about six self-selecting participants from a single department and one or two external facilitators. DATs meet regularly, typically for an hour every other week over multiple semesters. Participants are primarily faculty (both tenure-track faculty and fulltime instructors), but may also include staff, postdocs, graduate or undergraduate students, or other relevant stakeholders. Ideally, DAT participants are diverse along many different axes; the DATs in this study were diverse in terms of gender but not race, given the demographics of the relevant departments. DAT meetings include activities such as creating shared vision, interpreting data, strategizing about departmental politics, or meeting with departmental leaders or outside experts.

DAT facilitators support the participants in achieving their shared goal by bringing expertise in discipline-based education research (DBER) and institutional change to the group. Additionally, the facilitators provide logistical support (e.g., scheduling, note-taking, snacks), interface with other parts of the institution (e.g., requesting data sets from Institutional Research), and encourage collaboration, openness, and mutual respect among the participants. Being external to the department, the facilitators 
can ask questions that force participants to articulate unspoken assumptions about their department, leading to deeper self-reflection. The facilitators can also mitigate pre-existing status differentials among participants by treating them all on equal footing.

Empowerment of DAT participants is an important and intentional design feature. Therefore, the participants choose the DAT's area of focus, how they use their meeting time, and whether they assign themselves "homework." There is no predetermined "curriculum" for the DAT, although the facilitators do suggest how participants might use their time. This large amount of freedom helps participants to feel invested in work of their DAT.

\section{B. Design of a DAT}

The design of the DATs is grounded in the literatures on Faculty Learning Communities (FLCs) and on institutional change, which we discuss here.

\section{Faculty Learning}

Traditional approaches to developing faculty as teachers focus on disseminating knowledge of pedagogical advances through brief, one-way interactions (e.g., seminars or journal articles). In isolation, these approaches may raise awareness of such advances, but they rarely create lasting change in teaching practices [7]. For example, most faculty in physics are aware of research-based teaching methods [3], but most either ignore them or discontinue their use after trying them [4].

Faculty Learning Communities offer a more holistic approach to faculty development. An FLC is "a crossdisciplinary faculty and staff group of six to fifteen members ... who engage in an active, collaborative, yearlong program with a curriculum about enhancing teaching and learning" [8, p. 8]. In an FLC, each faculty member chooses an aspect of their teaching that they wish to improve, and the group mutually supports each other as they work towards achieving their individual goals. Ideally, the FLC becomes a community of practice [9] in which the group members use their interactions to learn about teaching and shift their identities as teachers.

Both FLCs and DATs leverage community and group learning to advance towards their goals. However, DATs differ from FLCs in a number of important ways. Because we view departments as the key unit of change in a university, DATs focus on a shared, broad-scale project in a single department rather than individual, course-level projects across multiple departments. Therefore, DAT members must be from the same department, and the broad-scale nature of the problem they seek to address means that the participation of non-faculty stakeholders is valuable, or perhaps essential, to the success of the team. Additionally, DATs have an explicit goal of sustainable change in their department rather than local changes in the participants' classrooms. Hence, the learning in the DAT focuses on how to create such changes rather than the details of any particular teaching method.

\section{Institutional Change}

DATs draw heavily on the institutional change literature. Many STEM change efforts are guided by implicit or even contradictory theories of change, which can limit their effectiveness [10]. In contrast, DATs are designed to align with what is known about institutional change. One way to organize the vast organizational change literature is to divide it into six perspectives: scientific management, evolutionary, social cognition, cultural, political, and institutional [11]. We have built each of these perspectives into the design of our DATs. These perspectives and their connections to the DATs are described in detail elsewhere [12]; however, we provide a brief sketch of some of these connections here.

Scientific management perspectives focus on using incentives and rewards to influence behavior. We secured course buyouts and/or service credit for DAT participants from their chairs to encourage their participation.

Social cognition perspectives focus on driving change by helping individuals to confront unconscious beliefs and prior worldviews with new information. We secured and analyzed data from our Institutional Research Office to replace hunches and anecdotes. The external facilitators helped participants to articulate the implicit beliefs they had about their department.

Cultural perspectives focus on aligning change efforts with existing cultural features. While the DAT process is different from that of a typical committees (e.g., facilitators rather than a chair), the fact that committees are part of departmental culture made it easier for faculty to understand the DATs.

Political perspectives focus on coalition-building, collective action, and leveraging existing power structures. We worked with existing departmental governance structures to form the DATs (e.g., presenting the DAT idea at a faculty meeting). Because the DAT is a team effort, it is inherently driven by collective action, and the group as a whole has more personal connections to leverage than any individual participant.

\section{ACTIVITIES AND OUTCOMES OF AN EXAMPLE DAT}

To illustrate how a DAT works in practice, we describe a DAT that we facilitated in a STEM department. This DAT consists of five participants: two tenured faculty members, two pre-tenure faculty members, and one postdoc who is the director of a community outreach program in the department. Three participants are male and two are female. While we did not collect information on how 
they self-identify, all of the participants could pass as white. To respect the participants' anonymity, we refer to the target department as "Potions."

We collected multiple types of data on this DAT: a brief mid-year survey (4 of 5 completed), extensive end of year interviews ( 2 of 5 completed, 3 scheduled), detailed meeting notes, emails between team members on the DAT's mailing list, and artifacts generated by the DAT (e.g., plots of student retention data and a final report to the department). Using a grounded theory approach, we provide a preliminary analysis of some of the themes that emerged from these data below.

\section{A. Summary of Activities}

We proposed forming a DAT to the Potions department chair in August 2014. The chair was receptive and invited our team to present at a faculty meeting to recruit participants. We did so on October 7, emphasizing that the topic of the DAT was not predetermined but would be chosen by the participants. Several faculty members brought up the underrepresentation of women and people of color in their department as a concern. This issue is highly relevant to disciplines like physics, engineering, and computer science. For example, the underrepresentation of women, people of color, and first-generation college students is significant among physics majors [2], and progress in achieving equity has stagnated and even regressed for some groups [13]. This lack of equity is a matter of social justice and leads to a systematic loss of students with the potential to be great scientists [14].

Several faculty members expressed interest in joining the DAT. Some said they would only join if it focused on equity; for example: "I signed up as interested in the DAT because of a specific area I'm interested in: trying to improve the experiences of women and underrepresented minority [Potions] majors. I thought the DAT might be a good way to work with a group to collect more information on where things stand now and think about changes and ways to track changes in the future."

The DAT had 15 hour-long meetings between October 28 and June 2. By the end of the first meeting, the participants had decided to make the underrepresentation of women and students of color their area of focus. The next few meetings focused on determining their specific goals and a plan for achieving them. Very quickly, the participants realized that they lacked data about the recruitment and retention of their majors. Despite anecdotal claims that the department lagged behind national diversity statistics, the participants had no idea if this was due to recruitment, retention, or both. There were also anecdotal claims that the department's honors-level introductory course is perceived as unapproachable by women students and that the department's homework help room is not utilized by students of color. Thus, data collection and analysis became the DATs priority. The DAT designed and administered a climate survey for majors graduating that December and a survey of help room use among students in the department's large introductory courses. The DAT also acquired a dataset from the university's Institutional Research office that included demographic and academic information on all Potions applicants and majors over the last decade.

DAT participants analyzed the collected data and reported their findings to the group over several meetings. The analysis provided insight into the academic trajectories of Potions students, including differences experienced by underrepresented students. During their last meetings, the team created a two-page summary of their findings and a list of recommendations to present at a faculty meeting. The DAT found that: "[w]omen and minorities interested in [Potions] are less likely to attend [our university] after acceptance," "[a]ttrition of [Potions] majors is significant for all students and is higher for women and minorities," and "[w]omen drop [Introductory Potions] the first time they take it at twice the rate of men." The DAT recommended creating a new departmental committee, as described below. The DAT is presently finalizing an extended version of its report.

\section{B. Outcomes of the DAT}

The DAT's main impact thus far was the creation, through a departmental faculty vote, of a Committee on Representation, Recruitment, and Retention $\left(\mathrm{R}^{3}\right)$ charged with learning about and acting on the underrepresentation of marginalized groups among the department's undergraduates. Three of the four DAT faculty participants have been assigned to this committee (with one as chair), and they have agreed that the committee should function as a continuation of the DAT. Additionally, both the DAT postdoc participant and the facilitators want to continue in their same roles in the $\mathrm{R}^{3}$ Committee. Our initial plan was for the DAT to run for a year; that the participants desire for it to continue for longer highlights the value that they felt for their work, their collaboration, and the DAT format.

The DAT participants intend to finish their report this summer and then disseminate it widely, not just to the department's faculty but also to its graduate students, postdocs, and staff. This report will support anyone in the department interested in developing initiatives to improve undergraduate equity. The DAT also plans to host a town hall meeting before the start of the fall semester to allow the department to understand the data more deeply and help the $\mathrm{R}^{3}$ Committee plan its work for the subsequent academic year (e.g., targeted recruitment of women and students of color, undergraduate focus groups and exit surveys to assess departmental climate).

The formation of the DAT was crucial to changing department structures. According to one of the tenured DAT participants, "[I]f they hadn't stood up at the faculty meeting and announced that there were resources to figure out some type of change to the department, then 
probably this wouldn't have happened."

\section{Participant Reflections on the DAT}

Participants reported enjoying the time they spent in DAT meetings: "I enjoyed talking with those people, I enjoyed thinking about those issues ... I liked to hang out with them for an hour every two weeks." They also reported that the DAT felt worthwhile and empowering: "It's valuable in that I feel like we are moving towards really effecting change." They valued being part of a group that shares their commitment to educational equity: "Why are so many of these things the DAT did ... not part of the department plan? ... It's frustrating to me that the [Potions] community here doesn't seem to care... So working with people who care ... that was just really nice. And I think I feel good about the outcomes that happened over the course of the year."

The external facilitators played a key role in the DAT. They provided logistical support, such as scheduling meetings, taking notes, and procuring snacks. They also kept the group moving forward: "They kept us on track. They made sure that there was communication all the time. They did what ... a typical faculty member won't do, which is to send emails and to hold people to a meeting schedule and to assign jobs." The facilitators also made the request of the Institutional Research Office (none of the DAT participants knew about this office) and analyzed some of the data.

Beyond logistics, the facilitators helped to manage the team's social interactions. Because they were external to departmental politics, they were able to mitigate power dynamics among the DAT participants: "Having [the facilitators] moderate the DAT seems to reduce any preexisting hierarchy among members of the DAT that exists from department structures. This is appreciated by us junior members!" At the same time, it was critical that the facilitators remain non-judgmental despite not being intimately aware of departmental culture and norms: "[S]o someone who was tone deaf might very well have come in and said you're at fifteen percent [women]? What the hell is wrong with you? So the need to match culturally to what the realities are and to not find them offensive but simply the reality, I think, allowed us to move on very quickly to let's find out what the numbers are, let's find out what we can learn."

Given the important role of external facilitators in the functioning of the DAT, it is important that the facilitators have adequate training and experience working with faculty to make the DAT successful. A detailed guide on facilitation of a DAT will be released in a forthcoming publication.

\section{CONCLUSION}

DATs show promise as a new tool for departments to use to improve their educational mission by supporting a group of faculty to create meaningful, sustained change. Simultaneously, DATs provide an opportunity for faculty members to work together productively, which could lead to a shift in the nature of collaboration within a department beyond the DAT. By providing a theoretical basis for a DAT and exemplifying its operation in a case example, we aim to help others utilize similar models in their departments to support educational change.

\section{ACKNOWLEDGMENTS}

We thank the Association of American Universities and the Helmsley Charitable Trust for funding this work. We also thank the Potions DAT participants for the time and energy they put into their work.
[1] President's Council of Advisors on Science and Technology, Engage to Excel: Producing One Million Additional College Graduates with Degrees in Science, Technology, Engineering, and Mathematics, Tech. Rep. (Executive Office of the President, 2012).

[2] National Research Council, Adapting to a Changing World-Challenges and Opportunities in Undergraduate Physics Education, Tech. Rep. (National Academy of Sciences, 2013).

[3] C. Henderson and M. H. Dancy, Phys. Rev. ST Phys. Educ. Res. 5, 020107 (2009).

[4] C. Henderson, M. Dancy, and M. Niewiadomska-Bugaj, Phys. Rev. ST Phys. Educ. Res. 8, 020104 (2012).

[5] C. Henderson and M. H. Dancy, Phys. Rev. ST Phys. Educ. Res. 3, 020102 (2007).

[6] A. A. for the Advancement of Science, Vision and Change in Undergraduate Biology Education: A Call to Action, Tech. Rep. (American Association for the Advancement of Science, 2011).

[7] C. Henderson, A. Beach, and N. Finkelstein, J. Res. Sci. Teach. 48, 952 (2011).

[8] M. D. Cox, New Dir. Teach. Learn. 2004, 5 (2004).

[9] E. Wenger, Communities of Practice: Learning, Meaning, and Identity (Cambridge University Press, 1998).

[10] E. Seymour, Sci. Educ. 86, 79 (2002).

[11] A. Kezar, How Colleges Change: Understanding, Leading, and Enacting Change (Routledge, 2013).

[12] J. C. Corbo, D. L. Reinholz, M. H. Dancy, S. Deetz, and N. Finkelstein, Phys. Rev. ST Phys. Educ. Res. (Submitted).

[13] P. J. Mulvey and S. Nicholson, Physics Bachelors Degrees: Results from the 2010 Survey of Enrollments and Degrees, Tech. Rep. (American Institute of Physics, 2012).

[14] E. Seymour and N. M. Hewitt, Talking about Leaving: Why Undergraduates Leave the Sciences (Westview Press, 1997). 